\title{
ROUSSEAU E O COURSIER INDOMPTÉ
}

Israel Alexandria Costa ${ }^{1}$

\section{Resumo:}

O presente artigo expõe uma leitura em torno de Jean-Jacques Rousseau que possa servir de contributo à pesquisa contemporânea junto a sua obra. A metodologia aplicada a essa leitura é o da análise históricofilosófica e hermenêutica, com vistas a desvendar a significação ética de uma passagem do Discours sur l'origine et les fondemens de l'inégalité parmi les hommes que trata do "coursier indompté", noção pouco explorada que, no texto original, articula-se com as noções de "homme barbare" e "orageuse liberté" para, respectivamente, formar um bloco de oposição ao "cheval dressé", ao "homme civilisé" e à "assujettissement tranquille". A hipótese de trabalho que inspira o desenvolvimento desta investigação é a de que o exame que evidencia as peculiaridades da crítica rousseauniana ao mal-estar da civilização e à moral social do seu século se constitui em via de conhecimento para aspectos fundamentais da inteira filosofia de Rousseau, assim como das questões de ética que o autor formulou de modo a jamais perderem a sua força e a sua atualidade.

Palavras-chave: Filosofia. Iluminismo. Rousseau. Ética.

\section{ROUSSEAU AND THE COURSIER INDOMPTÉ}

\begin{abstract}
:
This article presents a reading around Jean-Jacques Rousseau that can contribute to contemporary research in his work. The methodology applied to this reading is that of historical-philosophical and hermeneutic analysis, with a view to unraveling the ethical significance of a passage from Discours sur l'origine et les fondemens de l'inégalité parmi les hommes dealing with the "coursier indompté", little explored notion which, in the original text, articulates with those of "homme barbare" and "orageuse liberté" to form, respectively, a block of opposition to "cheval dressé", "homme civilisé" and "assujettissement" tranquille". The working hypothesis that inspires the development of this investigation is that the examination that highlights the peculiarities of the Rousseaunian critique of the malaise of civilization and the social morality of its century constitutes a way of knowledge for fundamental aspects of the whole philosophy of Rousseau, as well as the questions of ethics that the author formulated in such a way that they never lose their force and their actuality.
\end{abstract}

Keywords: Philosophy. Enlightenment. Rousseau. Ethic.

1 É mestre, doutor e pós-doutor em Filosofia pela Universidade Federal da Bahia, com produções desenvolvidas junto às linhas de pesquisa Ensino da Filosofia, Filosofia Política, Ética, Filosofia da Ciência, referenciadas sobretudo na perspectiva rousseauniana. Atualmente, é servidor público federal no cargo do magistério superior junto à Universidade Federal de Alagoas, onde atua como Professor Adjunto III lotado no Núcleo de Estudos Humanísticos Transdisciplinares do Campus Arapiraca. E-mail de contato: israel.costa@ arapiraca.ufal.br 


\section{INTRODUÇÃO}

"Rousseau nos previne explicitamente", afirma Bento Prado Júnior (2008, p. 91), "que seu discurso se dirige a auditórios particulares, que seu sentido e sua verdade não podem ser captados sem a consciência da 'situação retórica' na qual foi produzido". Esta afirmação dificilmente se vê desmentida junto à obra escolhida para esta análise, o Discurso sobre a origem e os fundamentos da desigualdade entre os homens, de 1753, em cuja Introdução se pode ler a frase: "homem de qualquer região que sejas, quaisquer que sejam tuas opiniões, ouve-me [...] É, por assim dizer, a vida de tua espécie que vou descrever" (ROUSSEAU, 1964, v. 3, p. 133).

Concordemos que essa afirmação não significa que o vasto auditório do Discurso efetivamente recebeu a mensagem, mas apenas que o autor pretende ser lido pelo lado humano de um leitor cuja humanidade se supõe escondida sob a capa das especificidades de cada região. Portanto, embora ciente de que o referido Discurso foi escrito originalmente em francês, porque destinado, em verdade, ao privilegiado auditório da sociedade parisiense do XVIII europeu, é preciso respeitar as advertências do comentador e do autor para considerar que o auditório do Discurso sobre a desigualdade seja, de fato, o homem de qualquer região e que é sob tal signo que devemos ouvi-lo se pretendemos aprender algo da vida da nossa espécie.

Para tanto, selecionamos uma passagem cuja natureza, método e finalidade são claros e simples: trata-se de uma peça retórica que agrega elementos do imaginário coletivo do francês setecentista quanto ao tema do coursier indompté para, operando uma demarcação radical entre o bárbaro e o civilizado, apresentar uma crítica radical à civilização e à moral social ao século XVIII que é válida ainda para a atualidade.

O trecho destacado como representativo desse tema encontra-se na segunda parte do Segundo Discurso - como também é referido o Discours sur l'origine de l'inégalité — a partir do qual traduzimos o termo indompté por "indômito" [e não "indomável", como sugere a tradução Lourdes Santos Machado, da Abril]:

Comme un coursier indompté hérisse ses crins, frappe la terre du pied et se débat impétueusement à la seule approche du mors, tandis qu'un cheval dressé souffre patiemment la verge et l'éperon, l'homme barbare ne plie point sa tête au joug que l'homme civilisé porte sans murmure, et il préfère la plus orageuse liberté à un assujettissement tranquille [como um corcel indômito eriça a crina, bate com o pé na terra e se debate impetuosamente só com a aproximação do freio, enquanto que um

\begin{tabular}{|c|c|c|c|c|}
\hline Rovista Dialectus & Ano 8 & n. 15 & Agosto - Dezembro 2019 & p. $88-96$ \\
\hline
\end{tabular}


cavalo domado aguenta pacientemente o chicote e a espora, também o homem bárbaro não dobra sua cabeça ao jugo que o homem civilizado carrega sem murmurar e prefere a mais tempestuosa liberdade a uma tranquila dominação] (ROUSSEAU, 1964, v. 3, p. 181, grifo nosso).

\section{DESENVOLVIMENTO}

Verifica-se que a operação lógica fundamental mobilizadora dos elementos implícitos e explícitos do excerto é basicamente a oposição. De um lado, manifesta-se a vivacidade do corcel indômito que eriça a crina e, do outro oposto, o quadro do cavalo domado cuja crina lhe cai pesadamente do pescoço arreado; um bate com os pés na terra e o outro está com os seus plantados no chão; um se debate violentamente só com a aproximação do freio, o outro aguenta pacientemente o chicote e a espora; um não dobra a sua cabeça ao jugo, o outro o carrega sem murmurar; etc.

Essas oposições figurativas, aqui colocadas a serviço da composição de dois retratos morais distintos, são os emblemas dos dois diferentes objetos de preferência dos sujeitos em questão: para um, esse objeto é a "tempestuosa liberdade"; para o outro, a "tranquila dominação". É uma questão de escolha quanto ao objeto a gozar da primazia, e essa escolha é decisiva para determinar a diferença entre o retrato do homem bárbaro, sob o emblema do coursier indompté, e o do homem civilizado, sob o do cheval dressé.

Pelo que tais decisões envolvem, a operação arquitetada por Rousseau abriga uma profunda significação moral. O objetivo do seu texto não se limita meramente a destacar uma diferença de condutas e de comportamentos entre tipos diferentes de um mesmo universo moral, e sim estabelecer uma demarcação radical na qual está em jogo a questão da moralidade em si mesma, pois o objeto da "preferência" aqui é um elemento ontologicamente constitutivo e irrenunciável do ser humano: a liberdade.

Inúmeras vezes Rousseau enfatiza que liberdade é qualidade essencial do humano. No Discurso sobre a desigualdade, a qualidade que se destaca da animalidade e é conhecida como um livre agir ${ }^{2}$ é chamada de qualidade humana; no Contrato Social, a liberdade é

2 "Em cada animal vejo somente uma máquina engenhosa a que a natureza conferiu sentidos para recompor-se por si mesma e para defender-se, até certo ponto, de tudo quanto tende a destruí-la ou estragá-la. Percebo as mesmas coisas na máquina humana com a diferença de tudo fazer sozinha a natureza nas operações do animal, enquanto o homem executa as suas como agente livre" (ROUSSEAU, 1964, v. 3, p. 141, grifo nosso).

\begin{tabular}{|l|l|l|l|l|}
\hline Qenista Dialectus & Ano 8 & n. 15 & Agosto-Dezembro 2019 & p. 88-96 \\
\hline
\end{tabular}


qualidade irrenunciável $^{3}$ do humano, por decorrer que a perda da liberdade implicaria a perda da própria qualidade humana. Sob tal perspectiva, enquanto o bárbaro preserva a sua alma humana ao preferir sacrificar a "tranquila dominação" a uma "tempestuosa liberdade", o civilizado perde a sua por preferir sacrificar a liberdade à tranquilidade.

Essa mensagem não era de difícil compreensão ao leitor setecentista, para quem o esplendor de um cavalo indomado era algo belo de se contemplar. Ainda que pudesse eventualmente ser pecebido como breve incômodo em uma administração que dependia de ungulados domados para o sistema de transporte, a imagem do coursier indompté, e tudo que ela representava, dobrava a Paris de Luís XV, brilhando e arejando nos salões em que a tediosa sociedade do luxo ansiava por algum contraponto de brutalidade e de selvageria.

Rousseau, portanto, aproveita-se de um imaginário que já existia antes dele, construído por uma longa tradição literária e poética de embelezamento dos cavalos selvagens. Em clássicos como a Ilíada, de Homero, pode-se ler passagens como "um garanhão [...] rompendo as correias sai galopando pelos campos a banhar-se no costumeiro rio, clara-corrente, e altivo ergue a cabeça, crinas soltas nas espáduas, e no esplendor da força os jarretes o levam à pastagem das éguas" (2002, VI, 510, p. 95), ou ainda "um cavalo, encerrado no estábulo, nutrido de cevada, farto, quando escapa do laço e galopando ganha as águas límpidas do rio onde se banha, ergue a cabeça e a crina soberba ondula sobre as espáduas; esplêndido, ele exulta, e a correr busca o pasto das éguas" (X, 265, p. 220), todas contribuindo para criar uma imagem favorável ao indompté que Rousseau explora na sua crítica.

E, a propósito de Homero, uma das mais importantes fontes literárias e poéticas do filósofo, cumpre observar que a imagem da força e da rebeldia selvagem do coursier indompté faz lembrar a própria saga de Aquiles, possuidor de um cavalo de sangue fogoso e ele próprio portador de um ânimo selvagem e esplendoroso. Curiosamente, tanto o Aquiles de Homero quanto o Coursier de Rousseau são destituídos de astúcia. O retrato moral de ambos, nesse aspecto, é inverso ao do filho de Laerte, o Odisseu dos mil ardis. Sob essa ótica, pode-se dizer que a passagem do coursier indompté, no Segundo Discurso, recoloca a questão homérica de saber qual modelo de homem é o mais excelente: o indômito ou o astuto.

O recorte alegórico pelo qual Rousseau busca representar o drama humano da

3 "Renunciar à própria liberdade é o mesmo que renunciar à qualidade de homem, aos direitos da Humanidade, inclusive aos seus deveres. Não há nenhuma compensação possível para quem quer que renuncie a tudo. Tal renúncia é incompatível com a natureza humana" (ROUSSEAU, 1964b, v. 3, p. 356, grifo nosso).

\begin{tabular}{|c|c|c|c|c|}
\hline Rovista Dialeatus & Ano 8 & n. 15 & Agosto - Dezembro 2019 & p. $88-96$ \\
\hline
\end{tabular}


"assujettissement tranquille", aqui traduzida por "tranquila dominação", é extraído do Homero da Odisseia. Na passagem 230 do Livro IX, o narrador é o próprio herói a contar que, com seus companheiros, passou a noite preso e sem fazer alarde no antro do monstro, gemendo, na expectativa da morte acerba, pois o Ciclope, o único com a força para libertá-los, acabara de agarrar e espargir os cérebros de dois companheiros no chão e estava dormindo, a digerir os membros rasgados e devorados para, na manhã seguinte, matar mais dois. A "tranquilidade dos companheiros de Ulisses trancados na caverna do Ciclope, esperando para serem devorados" é, para Rousseau (1964b, v. 3, p. 609), a representação perfeita do sofrimento que oprime ao ponto de determinar uma aparência de paz que, em verdade, é incapacitação da resistência ${ }^{4}$.

Daqui advém uma curiosa pista apresentada em um livro de Elias Canetti junto ao qual podemos vislumbrar o objeto que Rousseau tem em mente quando usa a expressão assujettissement tranquille ["tranquila dominação"]. Trata-se de um excerto de Massa e Poder, no qual o escritor búlgaro pensa a noção de melancolia com base em uma consideração que contempla o recorte mítico de Rousseau: "o melancólico não quer comer e, 92 como motivo para sua recusa, é possível que alegue não merecer comer. Na realidade, ele não quer comer porque pensa que ele próprio será comido" (1995, p. 348). Assim, parece ser, portanto, da melancolia que Rousseau fala quando, por "tranquilidade", refere-se à triste condição dos prisioneiros prestes a ser submergidos no estômago do seu devorador.

Outra fonte utilizada por Rousseau para delinear a natureza dessa "tranquila dominação", destacadamente o seu aspecto de subjugação silenciosa — uma tradução possível para assujettissement tranquille -, é o Tácito, de Histórias, de quem retira a expressão miserrimam servitutem pacem appellant [miserável escravidão que chamam de paz] com que batiza o fenômeno. $\mathrm{O}$ aspecto horroroso aqui enfatizado junto ao assujettissement tranquille é a desumanidade dos oprimidos, insinuada na metamorfose do sapiens livre em um ungulado servil que perdeu sua condição de sujeito do pacto social para dar lugar a uma criatura capturada pela força, derrotada pela violência e pela melancolia, no fundo incapaz de concordar ou não com o próprio aviltamento.

4 "Bem instruído de meus deveres e de minha felicidade, fecho os livros, saio da classe e olho ao redor de mim: vejo povos infortunados gemendo sob um jugo de ferro, o gênero humano esmagado por um punhado de opressores, uma multidão sobrecarregada de trabalho e faminta por pão, da qual o rico bebe em paz o sangue e lágrimas, e, em todo lugar, o forte armado contra o fraco do temível poder das leis. Tudo isso se faz pacificamente e sem resistência: é a tranquilidade dos companheiros de Ulisses trancados na caverna do Ciclope, esperando para serem devorados" (ROUSSEAU, 1964c, v. 3, p. 609, grifo nosso).

\begin{tabular}{|c|c|c|c|c|}
\hline Rovista Dialectus & Ano 8 & n. 15 & Agosto - Dezembro 2019 & p. $88-96$ \\
\hline
\end{tabular}


Finalmente, a simbologia do coursier indompté de Rousseau passa pelo tema do Secouer le joug [sacudir o jugo] pelo qual é possível definir a missão da própria filosofia iluminista. Secouer le joug é uma expressão consolidada no XVIII francês ${ }^{5}$, que aparece várias vezes nas obras de quase todos os grandes escritores da Enciclopédia, sobretudo para, em geral, destacar a demanda que Kant adotaria como fundamental ao próprio conceito de iluminismo ${ }^{6}$, de "sacudir o jugo" da autoridade em matéria de religião.

No interior da obra de Rousseau, secouer le joug é uma de suas chaves biográficas, na medida em que explica e justifica a irrupção do solitário no final da vida do escritor, a pensar que o protagonista de Os Devaneios representa o caminhante que, tendo "sacudido o jugo" da socialidade, se tornou solitário de uma solidão pós-social, semelhante à solidão pré-social do homme nature das origens. "Sacudir o jugo", sob tal simbologia, tornase o ato pelo qual uma moralidade injusta é submetida a uma reforma em respeito à natureza ética de um sujeito humano, portanto livre.

Embora o termo ética e os relativos às suas raízes idiomáticas não estejam literalmente presentes no texto sobre o coursier indompté, é preciso levar em conta uma 93 advertência, feita por Cassirer, de que Rousseau "foi o único ético absoluto que o século XVIII produziu" (1999, p. 69), de modo que a compreensão do caráter ético da referida passagem envolve um conhecimento acerca do espírito geral da obra do genebrino.

Com efeito, na passagem em análise, podemos compreender que está em jogo a ideia de uma natureza ética, não enquanto abstração moral, mas enquanto fato concernente à natureza dos cavalos selvagens que, passado o perigo da fuga - ou tão logo acreditam que ele tenha passado - retornam à vida despreocupada, cada animal fazendo o que lhe apraz (CANETTI, 1995, p. 317), pois o local onde o animal parou para fixar ali a sua 'morada', o

5 Segundo o Dictionnaire de l'Académie française, 6th Edition, "sacudir o jugo" significa "se défaire de quelque chose par un mouvement violent; c'est dans ce sens qu'on dit, qu'un taureau a 'secoué le joug'. Et on dit figurément, 'secouer le joug', pour dire, s'affranchir de la domination, se mettre en liberté. 'Secouer le joug' de la tyrannie. Quand les Romains secouèrent le joug des Tarquins. Ce jeune homme ne veut plus souffrir de tuteur, il veut 'secouer le joug'. On dit aussi figurément, 'secouer le joug' des passions, pour dire, s'affranchir de la tyrannie des passions [desfazer-se de algo por um movimento violento; é nesse sentido que se diz que um touro sacudiu o jugo. E diz-se, figurativamente, 'sacudir o jugo', para dizer, libertar-se da dominação, libertar-se. 'Sacudir o jugo' da tirania. Quando os romanos sacudiram o jugo dos Tarquinos. Esse jovem não quer mais sofrer com um tutor, ele quer 'sacudir o jugo'. Diz-se também figurativamente: 'sacudir o jugo' das paixões, dizer, libertar-se da tirania das paixões].

6 "Se, pois, se fizer a pergunta — Vivemos nós agora numa época esclarecida? — a resposta é: não. Mas vivemos numa época do Iluminismo. Falta ainda muito para que os homens tomados em conjunto, da maneira como as coisas agora estão, se encontrem já numa situação ou nela se possam apenas a vir a pôr de, em matéria de religião, se servirem bem e com segurança do seu próprio entendimento, sem a orientação de outrem" (KANT, 1988, p. 17).

\begin{tabular}{|c|c|c|c|c|}
\hline Ronita Dialectus & Ano 8 & n. 15 & Agosto - Dezembro 2019 & p. $88-96$ \\
\hline
\end{tabular}


seu habitat e o modo como ele o habita é, propriamente falando, o seu $\operatorname{ethos}^{7}$. Em Rousseau, a íntima relação entre ética e natureza é onipresente na crítica à moral do interesse social, de modo que o coursier indompté bem-sucedido em sua fuga, habitando o seu mundo de origem, livre dos jugos, é uma representação do homme naturel em seu espaço ético, livre da escravidão social que o subjuga.

Sem precisar ceder à provocação de Voltaire, segundo o qual "pode-se querer andar com quatro patas" (2008, p. 1) quando se lê o Discurso sobre a desigualdade, podemos conceder, com Starobinski, um paralelo entre o pasto do coursier indompté e a ilha de Saint Pierre, para propor que o indômito esteja no núcleo mais profundo da subjetividade do próprio Rousseau, destacadamente o de Os Devaneios, escritor completamente envolvido em sua obsessão poética de caminhante solitário, que se pensa como alguém que sacudiu o jugo em matéria de religião e, desacreditado de Deus, descansa na Ilha que toma por casa.

Nesse espaço ético da natureza, já desde o sacudir do jugo da domesticação, encena-se o encaixe cósmico da felicidade de um ser livre, que, tornando a existir no acordo consigo mesmo, desfruta da própria companhia e sente-se em casa no mundo, como que em merecido ócio após um trabalho acabado. O garanhão veloz, na alegria do aumento da sua potência de cavalo, no desejo e no gozo de estar no campo "onde o rio é ameno e as éguas pastam" é, na obra rousseauniana, uma das representações poéticas do esplendor ético de um povo ou de um indivíduo humano que respeita absolutamente os imperativos da sua natureza livre.

\section{CONCLUSÃO}

A título de considerações finais quanto ao trecho analisado, vale dizer que é possível ligá-lo a ensinamentos gerais do filósofo que repercutem na atualidade. Um desses ensinamentos é o de que devemos atentar para a escuta da natureza em nós, sobretudo em tempos de melancolia, na esperança de que o esplendoroso aconteça, não como ato heroico e solitário, mas coletivo e solidário. Apesar da acusação de misantropia de que Rousseau sofre por insistir no desatamento dos laços que nos unem a uma sociedade corrupta, o que essa proposta de escuta pretende é permitir ao indivíduo o estreitamento de laços com a humanidade de quem se avizinha como habitante da mesma morada.

7 "Encontrada pela primeira vez em Homero, a palavra ethos significava 'morada'. Não sendo arquitetura ou técnica de construção, ethos é habitat, 'toca', mas também o fato e a maneira de habitá-la" (MATOS, 2008, p. $75)$.

\begin{tabular}{|l|l|l|l|l|}
\hline Qenista Dialectus & Ano 8 & n. 15 & Agosto-Dezembro 2019 & p. 88-96 \\
\hline
\end{tabular}


Finalmente, na avaliação desse exame acerca da temática do coursier indompté no tocante ao que ele significa para a compreensão da obra de Jean-Jacques Rousseau, se poderia declarar não ser espantoso que, da sua teoria da bondade natural, não decorra a ideia de que a natureza selvagem e perpetuamente inovadora que cada homem abriga em si mesmo é bastante para, de um modo ético, salvá-lo do mal da subjugação.

\section{REFERÊNCIAS:}

CANETTI, E. Massa e poder. Tradução Sérgio Tellaroli. São Paulo: Cia das Letras, 1995.

CASSIRER, E. A questão Jean-Jacques Rousseau. Tradução Erlon José Paschoal. São Paulo: UNESP, 1999. 
HOMERO. Ilíada. Tradução Haroldo de Campos, São Paulo: Arx, 2002.

KANT, I. Resposta à pergunta: Que é Iluminismo? In: KANT, I. A Paz Perpétua e outros Opúsculos. Tradução Artur Morão. Lisboa: 70, 1988. p. 11-19.

MATOS, Olgária C. F. Ethos e Amizade: A morada do homem. PEPSIC: Periódicos Eletrônicos em Psicologia / Ide: Revista de psicanálise e cultura. São Paulo, v. 31, n. 146, p. 75-79, 2008.

PRADO JR., B. A Retórica de Rousseau. São Paulo: Cosac Naify, 2008.

ROUSSEAU, J.-J. Discours sur l'origine de l'inegalité. Paris: Gallimard, 1964. v. 3. p. 131194.

ROUSSEAU, J.-J. Discours sur les sciences et les arts. Paris: Gallimard, 1964a, v. 3, p. 330 .

ROUSSEAU, J.-J. Du Contrat Social ou Principes du Droit Politique. Paris: Gallimard, v. 3, 1964b. p. 351-470.

ROUSSEAU, J.-J. Émile ou de L'Éducation. Paris: Gallimard, 1969, v. 4, p. 239-868.

ROUSSEAU, J.-J. Que l'État de Guerre nait de l'état social. Paris: Gallimard, 1964c, v. 3, p. 601-612.

SECOUER. In: DICTIONNAIRE de l'Académie Française, 6ème édition, éditée en 1835. Chicago: University of Chicago / ARTFL Project / CNRTL - Centre National de Ressources Textuelles et Lexicales, 1982. Disponível em: https://cnrtl.fr/definition/academie8/secouer. Acesso em: 28 nov. 2019.

SPINELLI, M. Sobre as diferenças entre éthos com epsílon e êthos com eta. Trans/Form/Ação: Revista de Filosofia da Universidade Estadual Paulista / UNESP, São Paulo, v. 32, n. 2, p. 9-44, 2009. Disponível em: http://www.scielo.br/pdf/trans/v32n2/v32n2a01.pdf. Acesso em: 15 maio 2010. ISSN: 01013173

STAROBINSKI, J. Jean-Jacques Rousseau: a transparência e o obstáculo; seguido de sete ensaios sobre Rousseau. Tradução Maria Lúcia Machado. São Paulo: Companhia das Letras, 1991.

VOLTAIRE. Lettre a Jean-Jacques Rousseau: aux délices, près de Genève (30 août 1755), 2008. Disponível em: http://tecfa.unige.ch/proj/rousseau/voltaire.htm. Acesso em: 20 set. 2009.

\begin{tabular}{|l|l|l|l|l|}
\hline Qevista Dialectus & Ano 8 & n. 15 & Agosto-Dezembro 2019 & p. 88 - 96 \\
\hline
\end{tabular}

